\title{
Investors' Risk Preference Characteristics Based on Different Reference Point
}

\author{
Fenghua Wen, Zhifang He, Xu Gong, and Aiming Liu \\ School of Business, Central South University, Changsha, Hunan 410083, China \\ Correspondence should be addressed to Aiming Liu; liuaiming@csu.edu.cn
}

Received 6 January 2014; Accepted 12 March 2014; Published 9 April 2014

Academic Editor: Chuangxia Huang

Copyright (C) 2014 Fenghua Wen et al. This is an open access article distributed under the Creative Commons Attribution License, which permits unrestricted use, distribution, and reproduction in any medium, provided the original work is properly cited.

Taking the stock market as a whole object, we assume that prior losses and gains are two different factors that can influence risk preference separately. The two factors are introduced as separate explanatory variables into the time-varying GARCH-M (TVRAGARCH-M) model. Then, we redefine prior losses and gains by selecting different reference point to study investors' time-varying risk preference. The empirical evidence shows that investors' risk preference is time varying and is influenced by previous outcomes; the stock market as a whole exhibits house money effect; that is, prior gains can decrease investors' risk aversion while prior losses increase their risk aversion. Besides, different reference points selected by investors will cause different valuation of prior losses and gains, thus affecting investors' risk preference.

\section{Introduction}

Many studies suggest that investors' risk preference changes over time. When investors make decision under uncertainty in financial markets, prior outcomes of investors' can influence their risk preference, which can cause their decisionmaking behaviors to change. Studies as discussed in [1-4] believed that people's risk preference or risk aversion changed over time and the prior outcomes could influence their current decision making. And a similar finding in futures market that both prior losses and gains could affect investors' risk preference was reached in [5-7].

However, there is no agreement on what effects will prior outcomes have on investors' risk preference, which attracts an increasing number of scholars to study it. Early studies mainly focused on disposition effect which reflects the tendency to sell assets that have gained value and keep assets that have lost value. In other words, investors tend to be risk seeking with losses and risk averse with gains. Some scholars [8-10] supported the conclusion with experimental research, while some authors [11-13] proved this conclusion using actual trading data. Disposition effect was originally attributed to loss aversion which means that investors loathe losses and are willing to take greater risks to avoid further losses. However, based on the Prospect Theory proposed by Kahneman and
Tversky [14], studies [15-18] argued that investors were willing to take risk after prior gains, which was called "house money effect." Thaler and Johnson [15] pointed out that investors' behavior defied prediction and the editing rules were usually quite different, so it was hard to achieve agreement on this problem. Barberis and Xiong [19] studied the effect of prior losses and gains on current decision-making behaviors from a new perspective and they constructed a multiperiod model in which investors decided their risk preferences according to prior outcomes. They found that there was no disposition effect but in some cases investors' decision-making behaviors exhibit house money effect. Similarly, Hoffmann et al. [20] made a study on the evolution of risk behavior in a multiperiod decision context and showed how prior outcomes influenced subsequent choices. In recent studies, a lot of scholars adopted a more direct method to explore investor's risk-taking behavior after losses or gains. Coval and Shumway [21] found that futures traders in the Chicago Board of Trade were more willing to take risk after losses than gains. Frino et al. [6] qualitatively differentiated gains and losses with professional futures traders' actual trading data to compare their risk preference in the afternoon after gains and losses in the morning, respectively, for the purpose of testing the house money effect and the opposite behavior of loss aversion simultaneously; the empirical result 
showed that those investors' behavior supported the house money effect, but no proof of loss aversion was found. Mattos and Garcia [22] selected 12 traders' trading records in the agricultural futures and options market as sample to study continuous dynamic risk decision and they pointed out that, owing to investors' different reactions to prior gains of different investment portfolios, five traders exhibited the house money effect, and four traders showed loss aversion, while three traders' risk preferences were not influenced by prior gains. Using a set of transaction records from Taiwan Futures Exchange, Huang and Chan [23] examined risktaking behavior subject to prior outcomes and showed that the degree of morning gains/losses nonlinearly influences afternoon risk taking for all trader types.

When studying what effects will the prior outcomes have on the investors' risk preference, the selection of the reference point is critical. Kahneman and Tversky [14] believed that people's risk preferences varied and they usually chose a reference point to value the gain and the loss under uncertainties and had different risk preferences in the face of gains and losses. Thaler and Johnson [15] designed a series of questionnaires for experimental research and the result showed that people are more willing to gamble with prior gains; that is to say, the selection of reference point will affect prior loss and gain assessment, so as to affect risk preference. Tversky and Kahneman [24] pointed out that the value of a risk-return opportunity relied more on the selection of reference point than on the ultimate total return. Therefore, they claimed that people could manipulate people's decision by changing the reference point. Zhang [25] described that different selection of reference point would result in different expectations; therefore, it was impossible for behaviors drived by their expectation to conform the rational expectation theory.

The above literatures' analysis shows that, on the one hand, the research of what effects prior losses and gains have on investors' risk preference has not achieved agreement. Under the background of professional trading, Coval and Shumway [21], Frino et al. [6], and Mattos and Garcia [22] used regression models to explore how prior losses and gains affect current risk preference from the perspective of average market risk or extreme market risk. Lam and Ozorio [26] made an experimental betting game and investigated the gender risk-taking behavior with respect to prior outcomes in three distinct groups. In view of the bounded rationality of investors, the real market scenes can hardly be simulated through experiment and data of investors' transaction accounts usually are nonrepresentative because of the difficulty of obtaining. Thus, we take the entire stock market as the object, constructing the TVRA-GARCH-M model to study the effect of prior losses and gains on current risk preference and considered the problem raised by Frino et al. [6], which is that if prior losses and gains are treated as a continuous explanatory variable with both positive and negative values, it is impossible to decide whether the effect of prior losses and gains on investors' risk preference is the house money effect or loss aversion. On the other hand, in previous studies about the risk preference of investors, the selection of a reference point is subjective and there is no uniform criterion as to the selection of reference point.

In view of previous studies about the effect of prior losses and gains on investors' risk preference and about the selection of reference price being insufficient and inadequate, this paper utilizes ten worldwide representative indexes and uses prior losses and gains as separate explanatory variables to explore their overall effects on current risk preference in the entire market on the basis of TVRA-GARCH-M model. Then, we choose the historical high price, the historical low price, the 5 -day average price, the 20 -day average price, the 30-day average price, and the memory-adjusted price as the reference point, respectively, to further test investors' risk preference. On the one hand, this paper has overcome the demerits of the psychological experiments of Frino et al. [6], being hard to simulate the real market and having inadequate samples, and constructed the TVRA-GARCH$\mathrm{M}$ model. On the other hand, this paper has adopted six different reference prices, which makes up for the drawbacks that the subjective selection of reference point may result in conflicting conclusions.

This paper is organized as follows: the second part presents the model analysis; the third part provides the empirical study which includes the sample selection and the empirical result; the fourth part is the conclusion.

\section{The Model Analysis}

2.1. Selection of Reference Price. It should be pointed out that the reference price is a critical factor to the judgments of gains and losses. If the stock price exceeds the reference price, investors get gains or otherwise obtain losses. Reference price, as a kind of investors' psychological price, is different with personal evaluation criteria, and it is hard to determine which reference price is the most reasonable. Many researchers believe that investors usually take the average and extreme price as their reference points.

2.1.1. The Maximum Price and Minimum Price. Many researchers found that investors usually were affected by the historical highest or lowest price when measuring gains and losses. For example, studies as discussed in $[27,28]$ found that the historical highest price had significant influence on investors' decision in stock option market; Grinblatt and Keloharju [29] suggested that the highest and lowest price of the last month were important factors that could affect investors' trading behavior; Gneezy [30] studied disposition effect and discovered that investors tend to treat the historical highest price as the reference price when making investment decisions; Vinokur [31] adopted the 30-day highest price as the reference point to examine the disposition effect in the carbon market. In line with the circumstances of most stock markets, this paper takes 20 days as the average trading days for a month and then decides the maximum and minimum prices of every month as the reference points, which can be represented as

$$
\begin{aligned}
& R P_{t}=\operatorname{Max}\left(P_{t-1}, P_{t-2}, \ldots, P_{t-20}\right) \\
& R P_{t}=\operatorname{Min}\left(P_{t-1}, P_{t-2}, \ldots, P_{t-20}\right) .
\end{aligned}
$$


2.1.2. The Average Price. Anderson [32] and Mandler and Ritchey [33] suggested that investors tend to remember the average level instead of some particular details. Grinblatt and Han [34] took the weighted average price as the reference price of the investor when studying the disposition effect and momentum effect. In the stock market, full consideration should be given to people's practical operations during the process of investment when choosing reference price. And the moving averages as important trend indicators of technical analysis for securities are usually decisive factors for investors making stock trading. They tend to make decisions by analyzing these trend lines (5-day, 10-day, and 30-day average lines). Accordingly, this paper adopts the frequently used moving average prices of 5 days $\left(P_{t}^{5}\right), 10$ days $\left(P_{t}^{10}\right)$, and 30 days $\left(P_{t}^{30}\right)$ as investors' reference prices, which are estimated as

$$
\begin{aligned}
P_{t}^{5} & =\frac{1}{5}\left(P_{t-1}+P_{t-2}+\cdots P_{t-5}\right) \\
P_{t}^{10} & =\frac{1}{10}\left(P_{t-1}+P_{t-2}+\cdots P_{t-5}\right) \\
P_{t}^{30} & =\frac{1}{30}\left(P_{t-1}+P_{t-2}+\cdots P_{t-5}\right) .
\end{aligned}
$$

2.1.3. Memory-Adjusted Price. Kopalle and Lindsey-Mullikin [35] and Taudes and Rudloff [36] pointed out that the reference price would be affected by prior losses and gains, and people tend to adjust the current reference point according to the prior decision outcome. They believed that people would adjust their reference point as the following equation:

$$
m p_{t}=\alpha m p_{t-1}+(1-\alpha) p_{t-1}=\alpha\left(m p_{t-1}-p_{t-1}\right)+p_{t-1},
$$

where $\alpha(0 \leq \alpha<1)$ is a memory parameter and $m p_{t}$ is the reference price during $t$ period. $p_{t-1}$ is the stock price of last period, which means that people would adjust the current reference price with reference to the memory of the prior loss or gain on the basis of the last-period price. In view of the above, this paper takes the memory-adjusted price as investors' reference price, where the memory parameter $\alpha$ is set to be 0.2 according to the study made by Taudes and Rudloff [36].

\subsection{Model Construction}

2.2.1. The Time-Varying Risk Preference. In GARCH-M model, the risk premium coefficient in the mean equation represents the required compensation for each unit of risk. The larger the risk premium coefficient, the greater the compensation required by investors and the stronger the tendency to be risk averse. So the risk premium coefficient can be used to measure investors' risk preference [37]. However, according to behavioral financial theory, investors make different decisions and have different risk preference for gains and losses and they measure the gain and loss by comparing the stock price with the reference price. In prospect theory, the reference price is a key factor to determine the gain and loss. Therefore, reference price should also be taken into consideration when estimating the gain and loss which can influence invertors' risk preference, as is pointed out in [38]. We argue that the part of the stock price that exceeds the reference price, that is, $\left(p_{t}-r p_{t}\right)\left(p_{t}\right.$ and $r p_{t}$ are the stock price and the reference price), is the gain. And the part of the stock price that is below the reference price is the loss. We adjust $p_{t}-r p_{t}$ to the relative size $\left(p_{t}-r p_{t}\right) / r p_{t}$ with logarithmic form $\ln \left(p_{t-1}\right)-\ln \left(r p_{t-1}\right)$. Prior losses and gains will change with different reference prices adopted, and we construct the following TVRA-GARCH-M model:

$$
\begin{gathered}
r_{t}=c+x_{t} \cdot \beta+\gamma_{t} \sqrt{h_{t}}+\varepsilon_{t}, \\
\gamma_{t}=\rho_{0}+\rho_{1} \cdot \gamma_{t-1}+\rho_{2} \cdot \frac{s_{t-1}}{\sqrt{h_{t-1}}} \\
\varepsilon_{t}=\sqrt{h_{t}} \cdot v_{t}, \\
h_{t}=\alpha_{0}+\alpha_{1} \varepsilon_{t-1}^{2}+\theta_{1} h_{t-1},
\end{gathered}
$$

where $s_{t-1}=\ln \left(p_{t-1}\right)-\ln \left(r p_{t-1}\right), p_{t-1}$ and $r p_{t-1}$ are the prior stock price and reference price, $s_{t-1} / \sqrt{h_{t-1}}$ is the risk adjusted gain or loss of last period, $\rho_{0}$ is the fixed risk compensation required by investors for each unit of risk, which can be regarded as investors' inherent risk preference for a certain period of time, $\rho_{1}$ means that the current risk tolerance would be affected by that of the last period, which represents an average level of the current behavior affected by historical behavior, and $\rho_{2}$ denotes that people's risk preferences are subjected to the prior losses or gains. If $\rho_{2}$ is obviously less than zero, the compensation for risk will decrease with prior gains $\left(s_{t-1}>0\right)$, thus decreasing their extent of risk aversion, while, with prior losses $\left(s_{t-1}<0\right)$, the amount of their risk aversion will increase, or otherwise. Therefore, the risk compensation coefficient $\gamma_{t}$ is no longer fixed, but it changes with time and is affected by prior outcomes.

2.2.2. House Money Effect and Loss Aversion. Psychological experiments suggested that people's decisions exhibit asymmetry when facing gains and losses. Thaler and Johnson [15] have made multiperiod gambling experiments of real money to study the effect of prior losses and gains on investors' current risk preference. And they find that people were more willing to take risks after getting gains-risk-seeking, which is the so-called "house money effect." They also discovered that people are less willing to take risks with prior lossesrisk aversion. According to the behavioral finance theory, loss aversion shows that people's risk preference is inconsistent; that is, people are risk averse with gains and risk seeking with losses. In recent years, more studies of loss aversion are extended from single-period gambling to multiperiod of dynamic decision to study loss aversion. Frino et al. [6] have studied the effect of gains and losses in the morning on the degree of risk seeking in the afternoon with trading data from Sydney Futures Exchange. They suggested that the house money effect and loss aversion are symmetric antithesis, which was to say house money effect meant the morning gain would boost higher afternoon risk seeking, but 


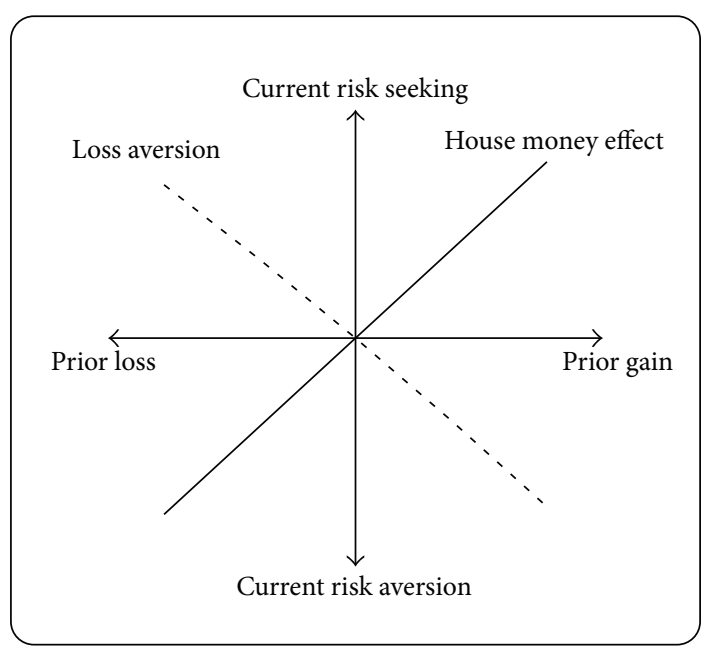

FIGURE 1: Hypothesized effects of prior loss and gain on current risk preference.

loss aversion meant the morning loss would enhance higher afternoon risk seeking. Mattos and Garcia [22] investigated trading behaviors in a dynamic frame and they suggested that five traders exhibited the house money effect and four investors showed risk aversion. Based on the above analysis, the house money effect and loss aversion are two separated psychological ways of motivation with regard to the effect of prior loss and gain on the current risk preference. Therefore, for the purpose of investigating the separated effect of prior losses and gains on time-varying risk preference, the key step is to examine the two psychological biases-the house money effect and loss aversion. For more visual effect, we illustrate it as in Figure 1.

Based on the TVRA-GARCH-M model, we further qualitatively distinguish the prior loss and prior gain: $s_{t-1}<0$ means the prior loss and $s_{t-1}>0$ shows the prior gain. In behavioral finance, there are many theoretical assumptions and empirical studies that have proved that the prior loss and the prior gain were two separated mental entities. The Sshaped value function proposed by Kahneman and Tversky [14] was based on people's different reactions to gains and losses when making risk decision. In the above TVRAGARCH-M model, the gain and loss were treated equally as a continuous explanatory variable with both positive and negative values. However, as Figure 1 shows, to some extent, equal amount of change in a prior loss and a prior gain has the equivalent but opposite effects on current risk preference.

In essence, if we only take the prior loss and the prior gain as values with different signs, but do not estimate them as separate explanatory variables in a model, it is impossible to test the house money effect $\left(\rho_{2}<0\right)$ and loss aversion $\left(\rho_{2}>0\right)$ at the same time. Besides, if the two biases exist simultaneously and with almost the same level of effect, the estimated coefficient for $\rho_{2}$ will be close to zero, thus making the two effects impossible to be tested.

Consequently, the following time-varying risk compensation coefficient model is derived on the basis of the above analysis to further test the house money effect and loss aversion simultaneously. We build the model called TVRASGARCH-M model as follows:

$$
\begin{gathered}
r_{t}=c+x_{t} \cdot \beta+\gamma_{t} \sqrt{h_{t}}+\varepsilon_{t}, \\
\gamma_{t}=\rho_{0}+\rho_{1} \cdot \gamma_{t-1}+\lambda_{11} \cdot \frac{s_{t-1}^{\prime}}{\sqrt{h_{t-1}}}+\lambda_{12} \cdot \frac{s_{t-1}^{\prime \prime}}{\sqrt{h_{t-1}}}, \\
\varepsilon_{t}=\sqrt{h_{t}} \cdot v_{t}, \\
h_{t}=\alpha_{0}+\alpha_{1} \varepsilon_{t-1}^{2}+\theta_{1} h_{t-1}, \\
s_{t-1}^{\prime}=s_{t-1}, \quad s_{t-1}>0, \\
s_{t-1}^{\prime \prime}=s_{t-1}, \quad s_{t-1}<0
\end{gathered}
$$

where $s_{t-1}$ is the prior gain or loss based on reference points, variables $s_{t-1}^{\prime}$ and $s_{t-1}^{\prime \prime}$ mean prior gains and losses, respectively, $s_{t-1}^{\prime} / \sqrt{h_{t-1}}$ is the risk adjusted gain of last period, and $s_{t-1}^{\prime \prime} / \sqrt{h_{t-1}}$ is the risk adjusted loss of last period. Parameter $\lambda_{11}$ reflects investors' demanding compensation for each unit of risk with prior gains and $\lambda_{12}$ denotes the compensation investors demanded for each unit of risk with prior losses.

\section{Empirical Study}

3.1. The Sample and Descriptive Statistics. In this paper, the sample data are the composite indexes of the top 10 market values in the global stock markets in 2011, including NYSE (USA), NASDAQ (USA), N225 (Japan), the FTSE 100 (UK), SSE (China), HSI (China), TSX (Canada), BOVESPA (Brazil), AORD (Australia), and DAX (Germany). The time span is from October 15, 2002, to October 15, 2012. All data are from Yahoo finance (http://finance.yahoo.com/). The return is expressed in logarithmic return $r_{t}=100 * \ln \left(p_{t} / p_{t-1}\right)$, where $r_{t}$ is the logarithmic return and $p_{t}$ is the adjusted closing price in stock market. The descriptive statistics are shown in Table 1.

According to the skewness, kurtosis, and J-B statistic of each index shown in Table 1, it can be seen that the return distributions of all indexes are skewed, and the Kurtosis values exceed that of a normal distribution, which shows that all the return distributions of all indexes are not normal.

\subsection{Empirical Evidence}

3.2.1. Results of TVRA-GARCH-M Model with Different Reference Points. Based on previous studies, investors' different reference points will affect the judgment of prior losses and gains, thus affecting investors' risk preference. Therefore, we select six reference points on the basis of the analysis in Section 2.2.1 and use the world's ten representative indexes for the maximum likelihood estimation of model (4) to examine the risk preference of the entire stock market.

Tables 2, 3, 4, 5, 6, and 7 show the TVRA-GARCH-M' estimation results, respectively, by taking the highest price per month (MAX), the lowest price per month (MIN), 5-day moving average price $\left(P_{t}^{5}\right), 10$-day moving average price $\left(P_{t}^{10}\right)$, 
TABLE 1: Descriptive statistics of returns.

\begin{tabular}{|c|c|c|c|c|c|c|}
\hline Statistic/index & Mean & Std. & Skewness & Kurtosis & JB statistic & Number \\
\hline NYSE & -0.020146 & 1.379473 & 0.386855 & 12.76570 & 10072.59 & 2519 \\
\hline NASDAQ & -0.034578 & 1.456799 & 0.178026 & 8.740239 & 3471.719 & 2519 \\
\hline N225 & 0.001421 & 1.548458 & 0.547135 & 11.61059 & 7697.198 & 2452 \\
\hline FTSE & -0.013400 & 1.265248 & 0.102467 & 10.37660 & 5729.256 & 2525 \\
\hline SSE & -0.013083 & 1.656866 & 0.246740 & 6.634653 & 1412.133 & 2519 \\
\hline HSI & -0.032618 & 1.605285 & -0.037799 & 12.15559 & 8749.820 & 2505 \\
\hline TSX & -0.025141 & 1.214611 & 0.680644 & 13.14799 & 10544.64 & 2414 \\
\hline $\mathrm{BOV}$ & -0.078359 & 1.861404 & 0.084820 & 8.040546 & 2623.075 & 2475 \\
\hline AORD & -0.016793 & 1.072880 & 0.553147 & 8.880106 & 3781.326 & 2535 \\
\hline DAX & -0.033998 & 1.539663 & -0.038525 & 8.105775 & 2773.715 & 2553 \\
\hline
\end{tabular}

TABLE 2: Results of TVRA-GARCH-M model (MAX).

\begin{tabular}{lccccccccccc}
\hline Index/parameter & NYSE & NASDAQ & N225 & FTSE & SSE & HSI & TSX & BOV & AORD & DAX \\
\hline$\rho_{0}$ & 0.129 & -0.055 & -0.033 & -0.317 & $0.008^{* *}$ & -0.061 & -0.091 & 0.248 & -0.130 & -0.070 \\
& {$[0.123]$} & {$[0.122]$} & {$[0.148]$} & {$[0.125]$} & {$[0.003]$} & {$[0.108]$} & {$[0.097]$} & {$[0.173]$} & {$[0.115]$} & {$[0.116]$} \\
$\rho_{1}$ & $-0.815^{* * *}$ & -0.406 & $-0.985^{* * *}$ & $-0.707^{* * *}$ & $0.979^{* * *}$ & -0.501 & 0.376 & $-0.979^{* * *}$ & -0.696 & $-0.984^{* * *}$ \\
& {$[0.128]$} & {$[0.957]$} & {$[0.011]$} & {$[0.203]$} & {$[0.008]$} & {$[0.719]$} & {$[0.603]$} & {$[0.021]$} & {$[0.494]$} & {$[0.009]$} \\
$\rho_{2}$ & $-2.503^{* * *}$ & -1.184 & -0.549 & $-3.251^{* * *}$ & $0.066^{* * *}$ & $-1.213^{*}$ & -1.162 & -0.492 & -1.572 & $-0.759^{*}$ \\
Likelihood & {$[0.732]$} & {$[0.922]$} & {$[0.409]$} & {$[0.884]$} & {$[0.024]$} & {$[0.711]$} & {$[1.091]$} & {$[0.401]$} & {$[1.012]$} & {$[0.430]$} \\
\hline
\end{tabular}

Note: $* * *, * *$, and $*$ in all tables denote that the parameter is significant at $1 \%, 5 \%$, and $10 \%$ level, respectively.

and 30-day moving average price $\left(P_{t}^{30}\right)$, and the memoryadjusted price (MP) as the reference points.

As is shown in the above tables, among the TVRAGA0RCH-M model estimation results with MAX, MIN, $P_{t}^{5}$, $P_{t}^{10}, P_{t}^{30}$, and MP as the reference points, the time-varying processes of risk compensation coefficient estimation results show that the estimated results for $\rho_{1}$ are mostly significant at the significance level of $10 \%$ with both positive and negative values for different composite indexes and different reference points, indicating that people's prior risk tolerance would have sustained effect on the current risk tolerance, but it cannot be decided whether the influence will be strengthened or decayed from the perspective of entire stock market. Moreover, the $\rho_{2}$ in most indexes are significantly negative. For those indexes with insignificant $\rho_{2}$, most of them are also negative with the exception of China's SSE (this may be due to the immaturity of China's stock markets), which indicates that in the stock market prior gains will bring down the current risk aversion and make investors become risk seeking, which shows the house money effect, while prior losses will push up the current risk aversion. Therefore, investors' risk preferences are time varying; the factors including prior gains and losses as well as prior risk tolerance will affect investors' current required risk compensation with each unit of risk.

Further observation shows that though the ten composite indexes as a whole show the house money effect, there are still some differences. For all indexes, when selecting different reference points, the same index does not have consistent value for $\rho_{1}$ and $\rho_{2}$. Taking the NYSE index as an example, the model estimation results with MAX, MIN, $P_{t}^{5}, P_{t}^{10}, P_{t}^{30}$, and MP as reference points are all significant and the sizes are $-0.815,-0.798,0.668,-0.556,-0.775$, and 0.777 for $\rho_{1}$ and $-2.503,-3.098,-1.735,-4.623,-2.807,-3.119$, and 3.119 for $\rho_{2}$. For the NASDAQ composite index, its $\rho_{1}$ results are -0.406 , $-0.473,-0.173$, and -0.265 , which are insignificant and 0.010 and 0.670 , which are significant. And $\rho_{2}$ results are -1.184 and -1.302, which are insignificant, and -2.270, -2.211, 27.024, and -2.003 , which are insignificant. All show that investors' risk preference is influenced by the selection of reference points. The prior loss and gains vary with different reference points, which to some extent will affect the investors' decision making.

3.2.2. Results of TVRAS-GARCH-M Model with Different Reference Points. With the empirical study described in Section 3.2.1, we get the TVRA-GARCH-M model results with different preference points. To further explore how the prior investment outcomes (gains and losses) influence the current risk preference on the basis of the analysis in Section 2.2, we further estimate the TVRAS-GARCH-M model with a variety of reference points. The results are shown in Tables $8,9,10,11,12$, and 13 .

The above tables (from Table 8 to Table 13) show that the entire stock market displays house money effect. Investors will become risk seeking with prior gains and risk averse with prior losses. Specifically, with six reference points, the parameter $\lambda_{11}$ or $\lambda_{12}$ is mostly significant, and most are significantly negative with the exception of one or two indexes. In Table 8 , parameter $\lambda_{11}$ is significantly negative, with the exception of SSE being significantly positive; Table 9 shows that parameters $\lambda_{12}$ are all significantly negative; Table 13 shows that $\lambda_{11}$ in eight indexes is significantly negative. In 
TABLE 3: Results of TVRA-GARCH-M model (MIX).

\begin{tabular}{lccccccccccc}
\hline Index/parameter & NYSE & NASDAQ & N225 & FTSE & SSE & HSI & TSX & BOV & AORD & DAX \\
\hline$\rho_{0}$ & $0.291^{* * *}$ & 0.154 & 0.070 & $0.349^{* * *}$ & -0.002 & 0.109 & 0.098 & $0.385^{* * *}$ & 0.088 & 0.046 \\
& {$[0.101]$} & {$[0.120]$} & {$[0.114]$} & {$[0.100]$} & {$[0.001]$} & {$[0.116]$} & {$[0.098]$} & {$[0.145]$} & {$[0.09]$} & {$[0.102]$} \\
$\rho_{1}$ & $-0.798^{* * *}$ & -0.473 & $-0.995^{* * *}$ & $-0.746^{* * *}$ & $0.982^{* * *}$ & -0.534 & 0.265 & $0.987^{* * *}$ & $-0.758^{* * *}$ & $-0.987^{* * *}$ \\
& {$[0.108]$} & {$[0.735]$} & {$[0.002]$} & {$[0.125]$} & {$[0.007]$} & {$[1.115]$} & {$[0.672]$} & {$[0.010]$} & {$[0.213]$} & {$[0.006]$} \\
$\rho_{2}$ & $-3.098^{* * *}$ & -1.302 & -0.409 & $-3.800^{* * *}$ & $0.056^{* * *}$ & -0.623 & -1.437 & $-0.601^{*}$ & $-2.587^{* *}$ & $-0.614^{*}$ \\
Likelihood & {$[0.832]$} & {$[0.880]$} & {$[0.274]$} & {$[0.947]$} & {$[0.020]$} & {$[0.666]$} & {$[1.278]$} & {$[0.360]$} & {$[1.068]$} & {$[0.334]$} \\
\hline
\end{tabular}

Note: $* * *, * *$, and $*$ in all tables denote that the parameter is significant at $1 \%, 5 \%$, and $10 \%$ level, respectively.

TABLE 4: Results of TVRA-GARCH-M model $\left(P_{t}^{5}\right)$.

\begin{tabular}{lcccccccccc}
\hline Index/parameter & NYSE & NASDAQ & N225 & FTSE & SSE & HSI & TSX & BOV & AORD & DAX \\
\hline$\rho_{0}$ & 0.008 & 0.060 & -0.001 & 0.075 & $0.271^{* * *}$ & 0.003 & -0.004 & 0.051 & -0.007 & 0.001 \\
& {$[0.018]$} & {$[0.082]$} & {$[0.020]$} & {$[0.106]$} & {$[0.001]$} & {$[0.010]$} & {$[0.016]$} & {$[0.051]$} & {$[0.013]$} & {$[0.018]$} \\
$\rho_{1}$ & $0.668^{* * *}$ & -0.173 & $0.728^{* *}$ & $0.898^{* *}$ & $-1.003^{* * *}$ & $0.833^{* * *}$ & $0.742^{* * *}$ & $0.577^{* *}$ & $0.761^{* * *}$ & $0.674^{* * *}$ \\
& {$[0.159]$} & {$[0.597]$} & {$[0.257]$} & {$[0.406]$} & {$[0.001]$} & {$[0.191]$} & {$[0.116]$} & {$[0.257]$} & {$[0.285]$} & {$[0.217]$} \\
$\rho_{2}$ & $-1.735^{* * *}$ & $-2.270^{*}$ & -0.698 & -0.164 & $0.229^{* * *}$ & -0.401 & $-1.800^{* * *}$ & $-1.137^{* *}$ & -0.708 & $-1.062^{* *}$ \\
Likelihood & {$[0.663]$} & {$[1.344]$} & {$[0.518]$} & {$[0.148]$} & {$[0.001]$} & {$[0.345]$} & {$[0.631]$} & {$[0.571]$} & {$[0.674]$} & {$[0.563]$} \\
\hline
\end{tabular}

Note: $* * *, * *$, and $*$ in all tables denote that the parameter is significant at $1 \%, 5 \%$, and $10 \%$ level, respectively.

TABLE 5: Results of TVRA-GARCH-M model $\left(P_{t}^{10}\right)$.

\begin{tabular}{lcccccccccc}
\hline Index/parameter & NYSE & NASDAQ & N225 & FTSE & SSE & HSI & TSX & BOV & AORD & DAX \\
\hline \multirow{2}{*}{$\rho_{0}$} & 0.064 & 0.054 & 0.0279 & 0.105 & $0.002^{* * *}$ & 0.040 & -0.008 & 0.080 & -0.053 & 0.005 \\
& {$[0.084]$} & {$[0.087]$} & {$[0.136]$} & {$[0.098]$} & {$[0.009]$} & {$[0.092]$} & {$[0.037]$} & {$[0.094]$} & {$[0.089]$} & {$[0.101]$} \\
$\rho_{1}$ & $-0.556^{* *}$ & -0.265 & $-0.889^{* * *}$ & $-0.736^{* * *}$ & $0.986^{* * *}$ & $-0.604(0.31)$ & $0.415(0.18)$ & $0.277(0.6)$ & $-0.786^{* * *}$ & $-0.984^{* * *}$ \\
& {$[0.219]$} & {$[0.625]$} & {$[0.089]$} & {$[0.124]$} & {$[0.002]$} & {$[0.597]$} & {$[0.313]$} & {$[0.579]$} & {$[0.201]$} & {$[0.009]$} \\
$\rho_{2}$ & $-4.623^{* * *}$ & $-2.211^{*}$ & $-1.939^{* *}$ & $-4.914^{* * *}$ & $0.112^{* * *}$ & $-1.227(0.13)$ & $-2.155^{* *}$ & $-1.139(0.18)$ & $-2.752^{* *}$ & $-0.768^{*}$ \\
\multirow{2}{*}{ Likelihood } & {$[1.051]$} & {$[1.238]$} & {$[0.894]$} & {$[1.197]$} & {$[0.025]$} & {$[0.822]$} & {$[1.086]$} & {$[0.860]$} & {$[1.406]$} & {$[0.458]$} \\
\hline
\end{tabular}

Note: $* * *, * *$, and $*$ in all tables denote that the parameter is significant at $1 \%, 5 \%$, and $10 \%$ level, respectively.

TABLE 6: Results of TVRA-GARCH-M model $\left(P_{t}^{30}\right)$.

\begin{tabular}{lcccccccccc}
\hline Index/parameter & NYSE & NASDAQ & N225 & FTSE & SSE & HSI & TSX & BOV & AORD & DAX \\
\hline \multirow{2}{*}{$\rho_{0}$} & 0.012 & $-0.990^{* * *}$ & -0.028 & 0.026 & $0.002^{* *}$ & 0.018 & -0.072 & $0.297^{*}$ & -0.086 & -0.012 \\
& {$[0.099]$} & {$[0.004]$} & {$[0.144]$} & {$[0.105]$} & {$[0.001]$} & {$[0.097]$} & {$[0.117]$} & {$[0.155]$} & {$[0.092]$} & {$[0.105]$} \\
$\rho_{1}$ & $-0.775^{* * *}$ & $0.010^{* * *}$ & $-0.896^{* * *}$ & $-0.791^{* * *}$ & $0.983^{* * *}$ & $-0.687(0.2)$ & $-0.773^{* * *}$ & $-0.983^{* * *}$ & $-0.739^{* *}$ & $-0.984^{* * *}$ \\
& {$[0.157]$} & {$[0.002]$} & {$[0.101]$} & {$[0.117]$} & {$[0.005]$} & {$[0.540]$} & {$[0.216]$} & {$[0.017]$} & {$[0.327]$} & {$[0.009]$} \\
$\rho_{2}$ & $-2.807^{* * *}$ & $27.024^{* * *}$ & $-1.448^{* *}$ & $-3.771^{* * *}$ & $0.049^{* * *}$ & $-0.999^{*}$ & $-2.595^{* * *}$ & $-0.499(0.2)$ & $-2.089^{* *}$ & $-0.738^{*}$ \\
\multirow{2}{*}{ Likelihood } & {$[0.737]$} & {$[0.246]$} & {$[0.662]$} & {$[0.896]$} & {$[0.014]$} & {$[0.586]$} & {$[0.882]$} & {$[0.390]$} & {$[1.001]$} & {$[0.420]$} \\
\hline
\end{tabular}

Note: $* * *, * *$, and $*$ in all tables denote that the parameter is significant at $1 \%, 5 \%$, and $10 \%$ level, respectively.

TABLE 7: Results of TVRA-GARCH-M model (MP).

\begin{tabular}{lcccccccccc}
\hline Index/parameter & NYSE & NASDAQ & N225 & FTSE & SSE & HSI & TSX & BOV & AORD & DAX \\
\hline$\rho_{0}$ & 0.006 & 0.012 & -0.001 & 0.105 & 0.118 & 0.001 & -0.004 & 0.026 & -0.023 & 0.001 \\
& {$[0.013]$} & {$[0.025]$} & {$[0.013]$} & {$[0.091]$} & {$[0.124]$} & {$[0.007]$} & {$[0.009]$} & {$[0.032]$} & {$[0.072]$} & {$[0.011]$} \\
$\rho_{1}$ & $0.777^{* * *}$ & $0.670^{* * *}$ & $0.821^{* * *}$ & $-0.671^{* * *}$ & -0.070 & $0.883^{* * *}$ & $0.857^{* * *}$ & $0.757^{* * *}$ & -0.489 & $0.807^{* * *}$ \\
& {$[0.101]$} & {$[0.245]$} & {$[0.164]$} & {$[0.191]$} & {$[0.963]$} & {$[0.141]$} & {$[0.074]$} & {$[0.178]$} & {$[0.413]$} & {$[0.144]$} \\
$\rho_{2}$ & $-3.119^{* * *}$ & $-2.003^{*}$ & -1.236 & $-3.418^{* *}$ & -0.962 & -0.693 & $-2.690^{* * *}$ & $-1.475^{* *}$ & -3.007 & $-1.605^{* *}$ \\
Likelihood & {$[0.984]$} & {$[1.141]$} & {$[0.797]$} & {$[1.504]$} & {$[0.928]$} & {$[0.590]$} & {$[0.933]$} & {$[0.746]$} & {$[1.842]$} & {$[0.811]$} \\
\hline
\end{tabular}

Note: $* * *, * *$, and $*$ in all tables denote that the parameter is significant at $1 \%, 5 \%$, and $10 \%$ level, respectively. 
TABLE 8: Results of TVRAS-GARCH-M model (MAX).

\begin{tabular}{lcccccccccc}
\hline Index/parameter & NYSE & NASDAQ & N225 & FTSE & SSE & HSI & TSX & BOV & AORD & DAX \\
\hline$\lambda_{11}$ & $-57.180^{* * *}$ & $-32.726^{* * *}$ & $-26.952^{* * *}$ & $-55.843^{* * *}$ & $1.239^{* *}$ & $-20.389^{* * *}$ & $-39.102^{* * *}$ & $-19.859^{* * *}$ & $-43.328^{* * *}$ & $-37.310^{* * *}$ \\
& {$[5.467]$} & {$[4.612]$} & {$[4.533]$} & {$[5.703]$} & {$[0.602]$} & {$[3.776]$} & {$[5.432]$} & {$[3.011]$} & {$[6.125]$} & {$[3.457]$} \\
$\lambda_{12}$ & $-0.990^{* *}$ & -0.410 & -0.343 & $-1.892^{* * *}$ & $0.030^{*}$ & -0.397 & $-1.091^{* * *}$ & -0.065 & -0.391 & $-0.705^{* *}$ \\
\multirow{2}{*}{ Likelihood } & {$[0.406]$} & {$[0.390]$} & {$[0.411]$} & {$[0.661]$} & {$[0.017]$} & {$[0.349]$} & {$[0.399]$} & {$[0.293]$} & {$[0.504]$} & {$[0.372]$} \\
\hline
\end{tabular}

Note: $* * *, * *$, and $*$ in all tables denote that the parameter is significant at $1 \%, 5 \%$, and $10 \%$ level, respectively.

TABLE 9: Results of TVRAS-GARCH-M model (MIN).

\begin{tabular}{lcccccccccc}
\hline Index/parameter & NYSE & NASDAQ & N225 & FTSE & SSE & HSI & TSX & BOV & AORD & DAX \\
\hline \multirow{2}{*}{$\lambda_{11}$} & $-1.422^{* * *}$ & -0.766 & -0.048 & $-2.029^{* * *}$ & $0.763^{* *}$ & -0.166 & $-1.047^{* *}$ & -0.445 & -1.446 & $-1.386^{* *}$ \\
& {$[0.555]$} & {$[0.635]$} & {$[0.129]$} & {$[0.752]$} & {$[0.332]$} & {$[0.224]$} & {$[0.467]$} & {$[0.532]$} & {$[1.024]$} & {$[0.720]$} \\
$\lambda_{12}$ & $-27.106^{* * *}$ & $-27.806^{* * *}$ & $-4.567^{* *}$ & $-38.036^{* * *}$ & $-21.988^{* * *}$ & $-11.127^{* * *}$ & $-33.931^{* * *}$ & $-19.841^{* * *}$ & $-27.990^{* * *}$ & $-13.520^{* * *}$ \\
Likelihood & {$[2.665]$} & {$[2.701]$} & {$[2.166]$} & {$[2.974]$} & {$[2.514]$} & {$[2.495]$} & {$[3.541]$} & {$[2.195]$} & {$[3.758]$} & {$[2.749]$} \\
\hline
\end{tabular}

Note: $* * *, * *$, and $*$ in all tables denote that the parameter is significant at $1 \%, 5 \%$, and $10 \%$ level, respectively.

TABLE 10: Results of TVRAS-GARCH-M model $\left(P_{t}^{5}\right)$.

\begin{tabular}{lcccccccccc}
\hline Index/parameter & NYSE & NASDAQ & N225 & FTSE & SSE & HSI & TSX & BOV & AORD & DAX \\
\hline \multirow{2}{*}{$\lambda_{11}$} & $-2.591^{* *}$ & $-3.778^{* *}$ & -0.895 & -0.115 & $0.240^{* * *}$ & -0.409 & $-2.992^{* * *}$ & $-1.690^{*}$ & -1.203 & $-2.486^{* *}$ \\
& {$[1.157]$} & {$[1.721]$} & {$[0.937]$} & {$[0.308]$} & {$[0.085]$} & {$[0.567]$} & {$[1.160]$} & {$[0.974]$} & {$[0.963]$} & {$[1.070]$} \\
$\lambda_{12}$ & -0.734 & -0.453 & -0.601 & -0.222 & $0.195^{* * *}$ & -0.396 & -0.577 & -0.531 & -0.072 & 0.127 \\
\multirow{2}{*}{ Likelihood } & {$[0.786]$} & {$[1.447]$} & {$[0.681]$} & {$[0.295]$} & {$[0.072]$} & {$[0.551]$} & {$[0.734]$} & {$[0.671]$} & {$[0.557]$} & {$[0.709]$} \\
\hline
\end{tabular}

Note: $* * *, * *$, and $*$ in all tables denote that the parameter is significant at $1 \%, 5 \%$, and $10 \%$ level, respectively.

TABLE 11: Results of TVRAS-GARCH-M model $\left(P_{t}^{10}\right)$.

\begin{tabular}{lcccccccccc}
\hline Index/parameter & NYSE & NASDAQ & N225 & FTSE & SSE & HSI & TSX & BOV & AORD & DAX \\
\hline$\lambda_{11}$ & $-5.448^{* * *}$ & -1.709 & $-2.752^{* *}$ & $-7.127^{* * *}$ & $2.640^{* * *}$ & $-1.553(0.2)$ & $-3.250^{* *}$ & $-0.521(0.3)$ & $-3.549^{*}$ & $-0.848(0.2)$ \\
& {$[1.795]$} & {$[1.700]$} & {$[1.120]$} & {$[1.881]$} & {$[1.036]$} & {$[1.338]$} & {$[1.627]$} & {$[0.615]$} & {$[2.081]$} & {$[0.698]$} \\
$\lambda_{12}$ & $-3.549^{* * *}$ & $-2.769^{* *}$ & $-0.866(0.3)$ & $-2.390^{*}$ & $-2.309^{* * *}$ & $-0.639(0.5)$ & $-0.844(0.2)$ & $-0.843(0.14)$ & $-2.075(0.18)$ & $-0.770^{*}$ \\
Likelihood & {$[1.268]$} & {$[1.417]$} & {$[0.855]$} & {$[1.436]$} & {$[0.923]$} & {$[0.997]$} & {$[0.781]$} & {$[0.572]$} & {$[1.567]$} & {$[0.465]$} \\
\hline
\end{tabular}

Note: $* * *, * *$, and $*$ in all tables denote that the parameter is significant at $1 \%, 5 \%$, and $10 \%$ level, respectively.

TABLE 12: Results of TVRAS-GARCH-M model $\left(P_{t}^{30}\right)$.

\begin{tabular}{|c|c|c|c|c|c|c|c|c|c|c|}
\hline Index/parameter & NYSE & NASDAQ & N225 & FTSE & SSE & HSI & TSX & BOV & AORD & DAX \\
\hline$\lambda_{11}$ & $\begin{array}{c}-4.933^{* * *} \\
{[1.427]}\end{array}$ & $\begin{array}{c}19.093^{* * *} \\
{[0.079]}\end{array}$ & $\begin{array}{c}0.709(0.4) \\
{[0.855]}\end{array}$ & $\begin{array}{c}-3.365^{* *} \\
{[1.710]}\end{array}$ & $\begin{array}{l}0.053^{* *} \\
{[0.027]}\end{array}$ & $\begin{array}{c}0.670 \\
{[1.068]}\end{array}$ & $\begin{array}{c}-2.840^{*} \\
{[1.638]}\end{array}$ & $\begin{array}{c}0.178(0.7) \\
{[0.529]}\end{array}$ & $\begin{array}{c}-2.637(0.12) \\
{[1.738]}\end{array}$ & $\begin{array}{c}-1.123(0.12) \\
{[0.734]}\end{array}$ \\
\hline$\lambda_{12}$ & $\begin{array}{c}-1.131(0.2) \\
{[0.920]}\end{array}$ & $\begin{array}{c}17.579^{* * *} \\
{[0.012]}\end{array}$ & $\begin{array}{c}-1.639(0.16) \\
{[1.190]}\end{array}$ & $\begin{array}{c}-4.008^{* * *} \\
{[1.095]}\end{array}$ & $\begin{array}{l}0.043^{*} \\
{[0.026]}\end{array}$ & $\begin{array}{c}-2.747^{* * *} \\
{[0.842]}\end{array}$ & $\begin{array}{c}-2.424^{* *} \\
{[1.117]}\end{array}$ & $\begin{array}{c}-0.852^{*} \\
{[0.527]}\end{array}$ & $\begin{array}{c}-1.728(0.17) \\
{[1.281]}\end{array}$ & $\begin{array}{c}-0.633(0.2) \\
{[0.496]}\end{array}$ \\
\hline Likelihood & -3556.580 & 2302.776 & -4063.584 & -3515.318 & -4413.475 & -4069.571 & -3282.142 & -4670.078 & -3142.121 & -4116.474 \\
\hline
\end{tabular}

Note: $* * *, * *$, and $*$ in all tables denote that the parameter is significant at $1 \%, 5 \%$, and $10 \%$ level, respectively.

TABLE 13: Results of TVRAS-GARCH-M model (MP).

\begin{tabular}{lcccccccccc}
\hline Index/parameter & NYSE & NASDAQ & N225 & FTSE & SSE & HSI & TSX & BOV & AORD & DAX \\
\hline$\lambda_{11}$ & $-4.051^{* * *}$ & $-5.176^{* * *}$ & $-4.207^{* *}$ & $-3.337^{* *}$ & -0.672 & $-3.300^{* *}$ & $-3.888^{* * *}$ & -1.743 & $-6.061^{* *}$ & $-4.664^{* * *}$ \\
& {$[1.378]$} & {$[1.987]$} & {$[1.773]$} & {$[1.341]$} & {$[0.509]$} & {$[1.561]$} & {$[1.471]$} & {$[1.218]$} & {$[2.578]$} & {$[1.771]$} \\
$\lambda_{12}$ & -1.887 & 1.389 & 0.761 & $-2.176^{*}$ & $1.097^{*}$ & 1.682 & -1.607 & 1.186 & 1.772 & 2.884 \\
\multirow{2}{*}{ Likelihood } & {$[1.202]$} & {$[1.923]$} & {$[1.825]$} & {$[1.153]$} & {$[0.599]$} & {$[1.712]$} & {$[1.188]$} & {$[1.338]$} & {$[2.669]$} & {$[1.833]$} \\
\hline
\end{tabular}

Note: $* * *, * *$, and $*$ in all tables denote that the parameter is significant at $1 \%, 5 \%$, and $10 \%$ level, respectively. 
Tables 10,11 , and 12 , half of the indexes have significantly negative $\lambda_{11}$ or $\lambda_{12}$, with the exception of the indexes SSE and NASDAQ in Table 12. Among them, parameters in SSE are significantly positive, which may be associated with the immaturity of China's stock markets. Compared with the estimation results with the other five reference points (MAX, MIN, $P_{t}^{5}, P_{t}^{10}, P_{t}^{30}$, and MP), the values for $\lambda_{11}$ and $\lambda_{12}$ of NASDAQ index in Table 13 estimated with the 30 -day moving average price $\left(P_{t}^{30}\right)$ as the reference point are positive, which may be related to the selection of reference points.

In addition, the values for $\lambda_{11}$ and $\lambda_{12}$ estimated with reference points are mostly significantly positive, but they still differ for different indexes. In all indexes, the results estimated with the highest month price, the lowest month price, and the memory-adjusted price as the reference points are generally more significant when compared with estimation results obtained with the 5-day, the 10-day, and the 30-day moving average prices as the reference points. Investors' risk aversion falls with prior gains, and the increase in investors' risk aversion is more obvious with prior losses. Specifically, the selection of reference points will affect the judgment of the prior gains and losses, thus affecting their risk preference. And we found that, for the parameters in some indexes that are not significant from Table 2 to Table 7 , the parameters $\lambda_{11}$ and $\lambda_{12}$ from Table 8 to Table 13 are significant. This phenomenon confirms the reasonability of the TVARSGARCH-M mode. Therefore, on the basis of TVAR-GARCH$\mathrm{M}$ model, we qualitatively separate the prior gains and losses to prove that the effect that prior losses and gains have on investors' risk preference is what the solid line shows in Figure 1, which shows that the stock market overall exhibits house money effect.

\section{Conclusion}

This paper, based on previous studies about investors' risk preference, selects ten representative samples of the world's composite indexes and adopts six different reference points and builds the TVARS-GARCH-M model to further explore how prior losses and gains affect investors' risk preference. First of all, the data in this paper are large enough, are easy to get, and are not affected by individual investor sentiments, so the results are more convincing. Secondly, this paper takes prior losses and gains as separate explanatory variables in the TVRA-GARCH-M model, overcoming the offsetting effect that the changes in prior gains and losses have on investors' current risk preference. That is, if we do not distinguish prior losses from gains, and when equal amounts of prior losses and prior gains have opposite but equivalent effects on the current risk preference, as shown in Figure 1, these two effects may cancel each other out, resulting in a false phenomenon that the prior loss and gain in essence do not affect the continuous risk seeking or risk aversion. Or, both the prior loss and gain increase investors' risk seeking or risk aversion with one of the effects being stronger than the other, and they may also offset each other. Finally, considering the possible influence arising from the subjective selection of reference points may affect investors' judgment of the risk; we select the six commonly used reference prices to study investors' risk preference, so the result is more robust.

Through the research, the following conclusions can be made. Firstly, from the overall stock market, investor's risk preference is time varying and can be affected by the prior outcome. Secondly, the stock market as a whole shows house money effect; namely, prior gains reduce the current risk aversion while prior losses push up the current risk aversion. Thirdly, the selection of different reference points affects the judgment of prior loss and gain, causing certain influence on the investors' risk preference.

\section{Conflict of Interests}

The authors declare that there is no conflict of interests regarding the publication of this paper.

\section{Acknowledgments}

This work was supported in part by the Natural Science Foundation of China (no. 71171024, no. 71371195, and no. 71221061). The authors gratefully acknowledge the helpful work of postgraduate Mengxian Tao, who has made great contribution to this paper.

\section{References}

[1] K. Keasey and P. Moon, "Gambling with the house money in capital expenditure decisions: an experimental analysis," Economics Letters, vol. 50, no. 1, pp. 105-110, 1996.

[2] P. Sadorsky, "Time-varying risk premiums in petroleum futures prices," Energy Economics, vol. 24, no. 6, pp. 539-556, 2002.

[3] A. Y. Javid, "Time varying risk return relationship: evidence from listed Pakistani firms," European Journal of Scientific Research, vol. 22, no. 1, pp. 16-39, 2008.

[4] J. Kostek and L. Ashrafioun, "Tired winners: the effects of cognitive resources and prior winning on risky decision making," Journal of Gambling Studies, 2013.

[5] P. R. Locke and S. C. Mann, "Professional trader discipline and trade disposition," Journal of Financial Economics, vol. 76, no. 2, pp. 401-444, 2005.

[6] A. Frino, J. Grant, and D. Johnstone, "The house money effect and local traders on the Sydney Futures Exchange," Pacific Basin Finance Journal, vol. 16, no. 1-2, pp. 8-25, 2008.

[7] Y.-J. Liu, C.-L. Tsai, M.-C. Wang, and N. Zhu, "Prior consequences and subsequent risk taking: new field evidence from the Taiwan futures exchange," Management Science, vol. 56, no. 4, pp. 606-620, 2010.

[8] M. Weber and C. F. Camerer, "The disposition effect in securities trading: an experimental analysis," Journal of Economic Behavior and Organization, vol. 33, no. 2, pp. 167-184, 1998.

[9] M. S. Haigh and J. A. List, "Do professional traders exhibit myopic loss aversion? An experimental analysis," Journal of Finance, vol. 60, no. 1, pp. 523-534, 2005.

[10] M. Weber and H. Zuchel, "How do prior outcomes affect risk preference? Comparing escalation of commitment and the house-money effect," Decision Analysis, vol. 2, no. 1, pp. 30-43, 2005. 
[11] H. Shefrin and M. Statman, "The disposition to sell winners too early and ride losers to long: theory and evidence," Journal of Finance, vol. 40, no. 3, pp. 777-790, 1985.

[12] T. Odean, "Are investors reluctant to realize their losses?" Journal of Finance, vol. 53, no. 5, pp. 1775-1798, 1998.

[13] D. Jordan and J. D. Diltz, "Day traders and the disposition effect," The Journal of Behavioral Finance, vol. 5, no. 4, pp. 192200, 2004.

[14] D. Kahneman and A. Tversky, "Prospect theory: an analysis of decision under risk," Econometrics, vol. 47, no. 2, pp. 263-291, 1979.

[15] R. H. Thaler and E. J. Johnson, "Gambling with the house money and trying to break even: the effects of prior outcomes on risky choice," Management Science, vol. 36, no. 6, pp. 643-660, 1990.

[16] M. Massa and A. Simonov, "Behavioral biases and investment," Review of Finance, vol. 9, no. 4, pp. 483-507, 2005.

[17] L. F. Ackert, N. Charupat, B. K. Church, and R. Deaves, "An experimental examination of the house money effect in a multiperiod setting," Experimental Economics, vol. 9, no. 1, pp. 5-16, 2006.

[18] Y. L. Hsu and E. H. Chow, "The house money effect on investment risk taking: evidence from Taiwan," Pacific-Basin Finance Journal, vol. 21, no. 1, pp. 1102-1115, 2013.

[19] N. Barberis and W. Xiong, "What drives the disposition effect? An analysis of a long-standing preference-based explanation," Journal of Finance, vol. 64, no. 2, pp. 751-784, 2009.

[20] A. O. I. Hoffmann, S. F. Henry, and N. Kalogeras, "Aspirations as reference points: an experimental investigation of risk behavior over time," Theory and Decision, vol. 75, no. 2, pp. 193-210, 2013.

[21] J. D. Coval and T. Shumway, "Do behavioral biases affect prices?" Journal of Finance, vol. 60, no. 1, pp. 1-34, 2005.

[22] F. Mattos and P. Garcia, "The effect of prior loss and gain on current risk-taking using quantile regression," in Proceedings of the NCCC134 Conference on Applied Commodity Price Analysis, Forecasting, and Market Risk Management, St. Louis, Mo, USA, 2009.

[23] Y. C. Huang and S. H. Chan, "The house money and breakeven effects for different types of traders: evidence from Taiwan futures markets," Pacific-Basin Finance Journal, vol. 26, pp. 1-13, 2014.

[24] A. Tversky and D. Kahneman, "Advances in prospect theory: cumulative representation of uncertainty," Journal of Risk and Uncertainty, vol. 5, no. 4, pp. 297-323, 1992.

[25] Y. Zhang, "Prospect theory and its application," Consume Guide, vol. 16, pp. 225-226, 2008.

[26] D. Lam and B. Ozorio, "The effect of prior outcomes on gender risk-taking differences," Journal of Risk Research, vol. 16, no. 7, pp. 791-802, 2013.

[27] C. Heath, S. Huddart, and M. Lang, "Psychological factors and stock option exercise," Quarterly Journal of Economics, vol. 114, no. 2, pp. 601-627, 1999.

[28] A. M. Poteshman and V. Serbin, "Clearly irrational financial market behavior: evidence from the early exercise of exchange traded stock options," Journal of Finance, vol. 58, no. 1, pp. 3770, 2003.

[29] M. Grinblatt and M. Keloharju, "What makes investors trade?" Journal of Finance, vol. 56, no. 2, pp. 589-616, 2001.

[30] U. Gneezy, Updating the Reference Level: Experimental Evidence, Experimental Business Research, 2005.

[31] L. Vinokur, "Dispositon in the carbon market and institutional constraints," Working Paper, 2009.
[32] J. R. Anderson, "Verbatim and propositional representation of sentences in immediate and long-term memory," Journal of Verbal Learning and Verbal Behavior, vol. 13, no. 2, pp. 149-162, 1974.

[33] J. M. Mandler and G. H. Ritchey, "Long-term memory for pictures," Journal of Experimental Psychology: Human Learning and Memory, vol. 3, no. 4, pp. 386-396, 1977.

[34] M. Grinblatt and B. Han, "Prospect theory, mental accounting, and momentum," Journal of Financial Economics, vol. 78, no. 2, pp. 311-339, 2005.

[35] P. K. Kopalle and J. Lindsey-Mullikin, "The effect of external reference price on consumer price expectations," Journal of Retailing, vol. 79, no. 4, pp. 225-237, 2003.

[36] A. Taudes and C. Rudloff, "Integrating inventory control and a price change in the presence of reference price effects: a twoperiod model," Mathematical Methods of Operations Research, vol. 75, no. 1, pp. 29-65, 2012.

[37] F. Wen and X. Yang, "Skewness of return distribution and coefficient of risk premium," Journal of Systems Science \& Complexity, vol. 22, no. 3, pp. 360-371, 2009.

[38] F. Wen, Z. He, and X. Chen, "Investors' risk preference characteristics and conditional skewness," Mathematical Problems in Engineering, vol. 2014, Article ID 814965, 14 pages, 2014. 


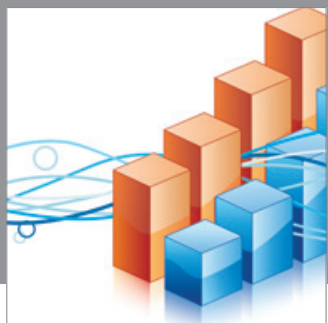

Advances in

Operations Research

mansans

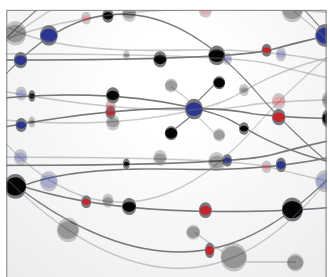

The Scientific World Journal
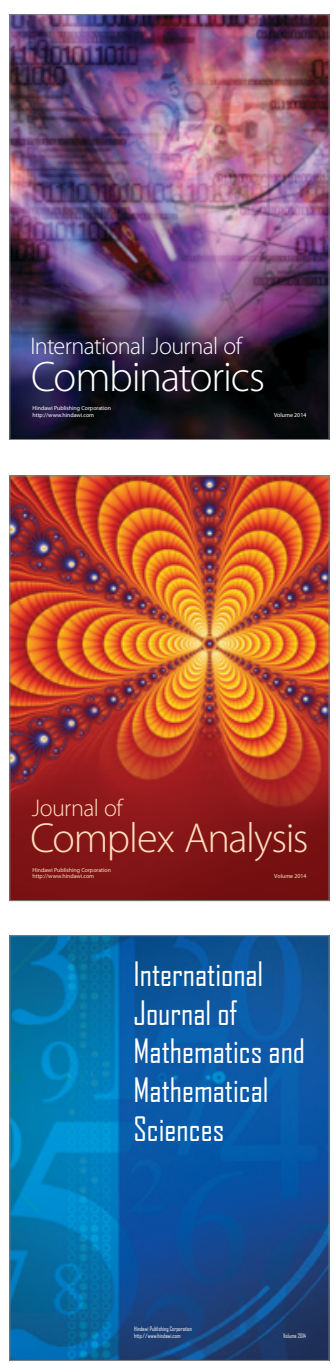
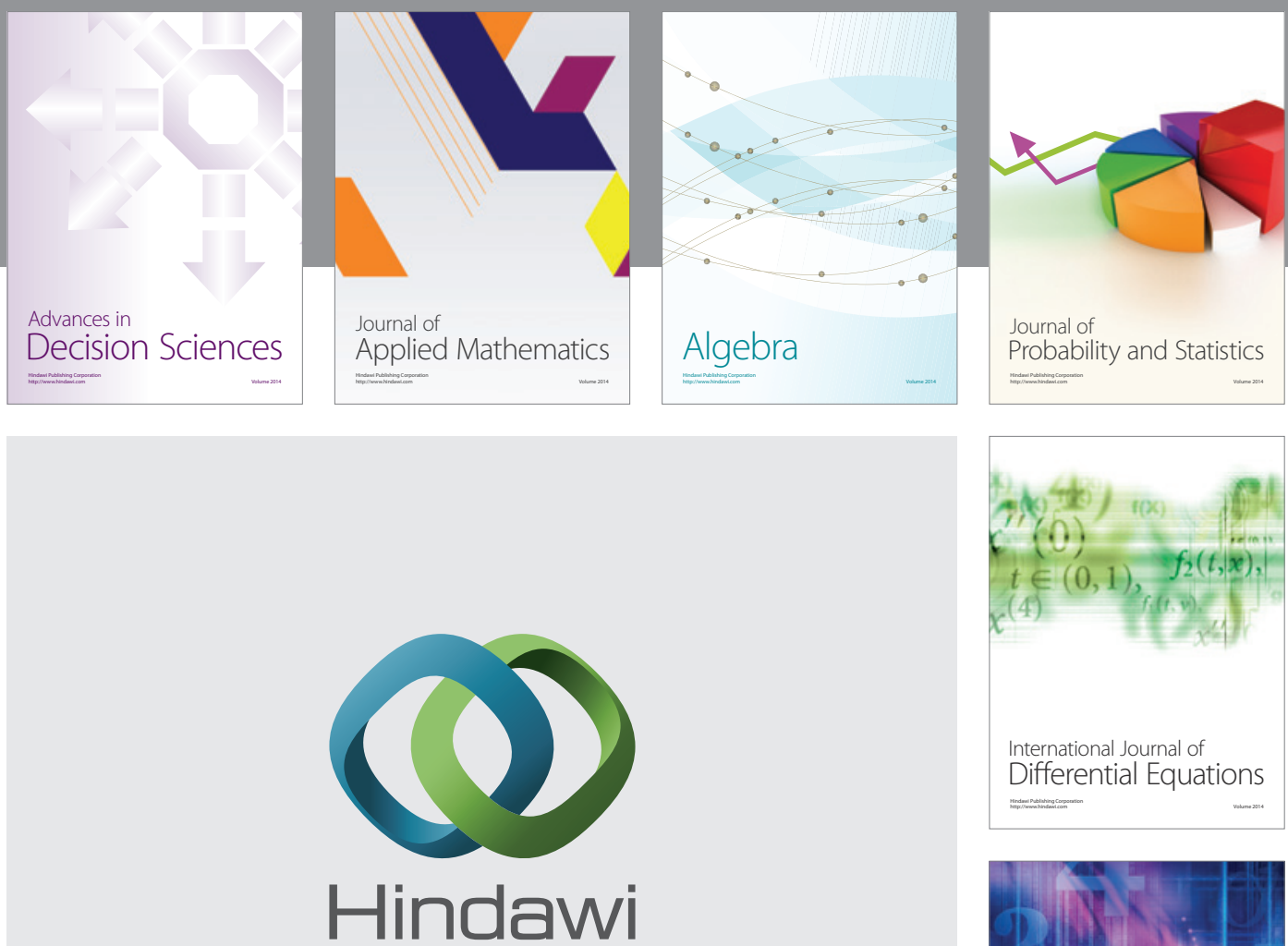

Submit your manuscripts at http://www.hindawi.com
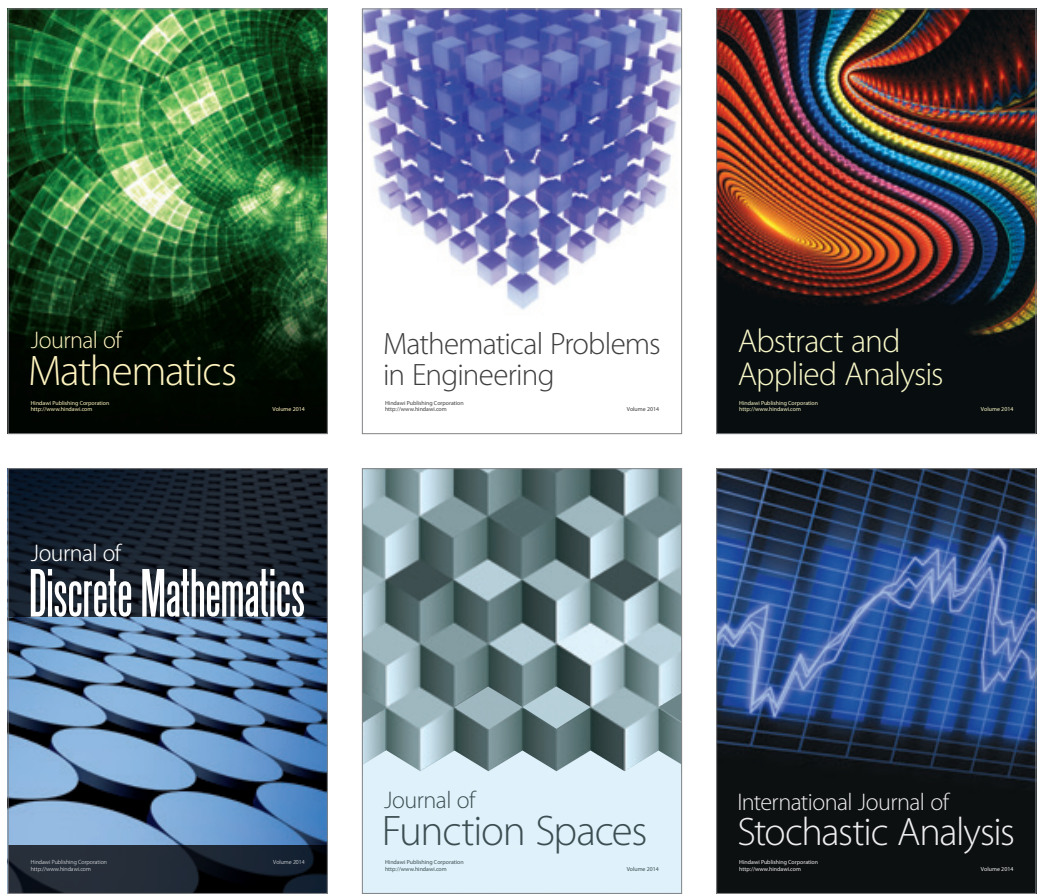

Journal of

Function Spaces

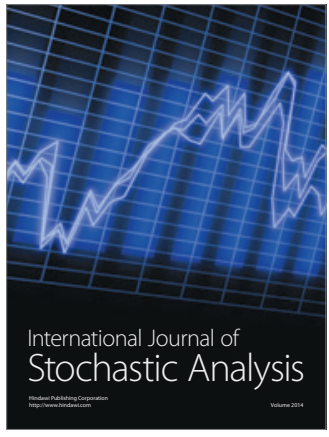

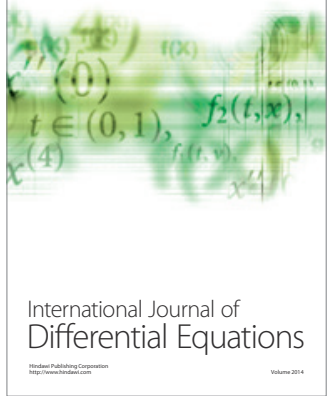
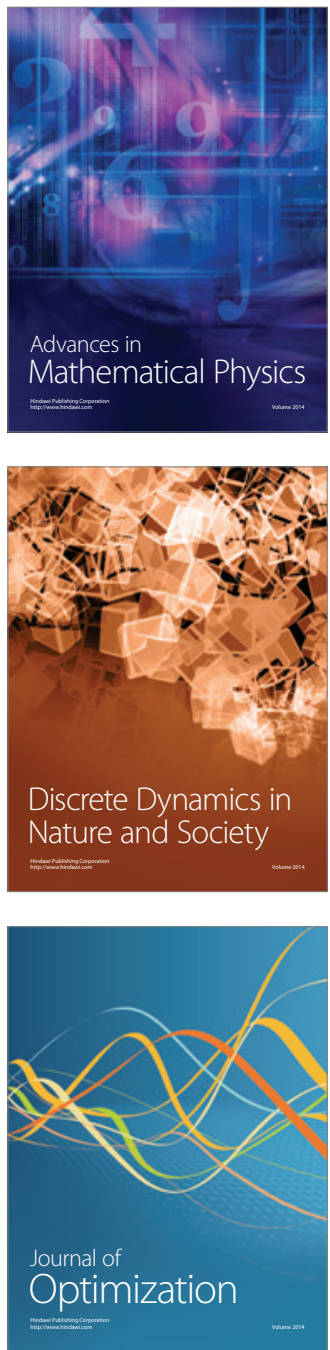